\title{
Scoring system in outcome prediction of postoperative mortality and morbidity in perforated peptic ulcer
}

\author{
Sah $\mathrm{DN}^{1 *}$ and Upadhyay $\mathrm{PK}^{2}$ \\ ${ }^{1}$ Institute of Medicine, TU Teaching Hospital, Nepal \\ ${ }^{2}$ National Academy of Medical Sciences, Nepal
}

\begin{abstract}
Introduction: Accurate and early identification of Perforated Peptic Ulcer (PPU) patients with an increased risk of adverse outcome is needed to plan and target the level of perioperative monitoring and treatment. To provide optimal care, it is important to stratify patients into high and low categories ideally prior to surgery. The purpose of the study is to compare the accuracy of various scoring systems (Boey, PULP, ASA, MPI) in predicting morbidity and mortality in PPU. Such risk stratification study in prospective design will guide in choosing best scoring in developing countries.
\end{abstract}

Materials and methods: This prospective observational study conducted at BIR hospital, NAMS, Nepal for a period of 16 months from October 2014 - January 2016. A total of 50 cases undergoing emergency surgery for PPU were included. Clinical presentations, scoring and surgical outcomes were analyzed. Receiver-operating characteristic curve (ROC) analysis was used to compare predictive ability of scoring systems.

Results: Thirty days' mortality was $18 \%$ while postoperative morbidity recorded in $64 \%$. ROC curve revealed Boey score area under curve (AUC) mortality prediction (0.802); morbidity (0.778) while PULP score AUC mortality (0.810); morbidity (0.829). Mortality prediction with Boey \& PULP score was better than MPI and ASA. However, ASA predicted morbidity is better (0.842). Patients with morbidity and mortality had statistically significant higher mean \pm S.D value of scores.

Conclusions: Early presentation, prompt diagnosis and emergent surgery are the pillars to successful management and good outcomes of PPU. The Boey and PULP score can be utilized as simple and precise predictor of postoperative mortality and morbidity in PPU patients.

\section{Introduction}

Annually peptic ulcer disease (PUD) affects 4 million people globally out of which complications developed in $10-20 \%$, and $2-14 \%$ of the ulcers will perforate [1]. In contrary to bleeding, perforation is the most common cause of mortality and morbidity and mortality rates of $25-30 \%$ have been reported in literature [2,3]. Surgery is the preferred mode of treatment of perforated peptic ulcer (PPU) peritonitis. In the era of successful eradication with $H$. pylori treatment and better understanding of the pathophysiology of peptic ulcer, formal acid-reducing procedures like vagotomy with or without drainage procedures, are now being replaced by simpler procedures, such as omental patch primary closure of the perforation.

Progressive increasing age, severe medical co-morbidities, perioperative shock and delay in diagnosis and management are associated with adverse outcomes [4]. To improve the outcomes, it is important to categorize patients based on risk of developing morbidities and mortalities, so that high-risk patients can receive more appropriate treatment and better intensive care. Different perioperative risk scores have been developed for PPU patients [5-8]. Boey score [6] (0-3) based on the presence of major medical illness, preoperative shock, and perforation longer than $24 \mathrm{hr}$. The in-hospital mortality proportion increased progressively with the number of prognostic variables, being $0 \%, 10 \%, 45.5 \%$, and $100 \%$ in patients with none, one, two, or all three variables, respectively as published by Boey et al [6]. Peptic Ulcer Perforation (PULP) score [9] (0-18) in which seven factors are taken into account. American Society of Anesthesiologists (ASA) score $[10,11](\mathrm{I}-\mathrm{V})$ the patient's preoperative health status, independent of the current surgical disease, is classified in five categories. The Mannheim Peritonitis Index (MPI) [12,13] (0-47) multivariable system with eight adverse factors which comprises both preoperative and perioperative conditions. Other scoring systems found in literature include Hacettepe score, Jabalpur score, APACHE II, POSSUM. In circumstances of a limited number of ICU, high dependency unit beds and large number of referrals from all over the country as in our hospital set up, individual risk stratification is of prime importance. Also, most of the studies have been in retrospective design and no one published regarding scoring comparison from low resource countries like Nepal.

The aim of the study is to compare the accuracy of various scoring systems (Boey, PULP, ASA, MPI) in predicting mortality and morbidity in PPU.

\section{Methods}

This was a Prospective observational/ non-interventional study conducted at Department of Surgery, National Academy of Medical Sciences (NAMS), Bir Hospital, Mahaboudha, Kathmandu, Nepal from October 2014 to January 2016 for 16 months' duration. Inclusion criteria were all perforated peptic ulcer with age $\geq 16$ years with clinically \&

*Correspondence to: Dhruba Narayan Sah, Institute of Medicine, TU Teaching Hospital, Kathmandu, Nepal, Tel: 97-798-605-551-98, E-mail: drshah_dn@live.com

Key words: perforated peptic ulcer, scoring, Boey, PULP, NAMS

Received: August 14, 2018; Accepted: September 11, 2018; Published: September 17, 2018 
radiologically suspected cases of PPU and/ or intraoperative diagnosed cases of perforation over duodenum and stomach. Exclusion criteria were perforation owing to trauma, non-surgically treated patients or unfit for general anesthesia, not giving consent, patient follow up criteria not met. Ethical approval was taken from Institutional Review Board (IRB, NAMS). Convenience sampling technique was used for sample size calculation in the defined period. A written informed consent was taken from all patients. Definitive diagnosis was made on explorative laparotomy by finding duodenal/ gastric perforation. The strategy of PPU treatment in our hospital was to perform primary closure of the perforation with classical or modified Graham's patch omentopexy. Gastric resection with gastrojejunostomy or gastrojejunostomy with primary repair was performed in the case of perforated proximal gastric ulcer or large perforated ulcer (diameter $>20 \mathrm{~mm}$ ), depending on the surgeon's intraoperative decision. Each patients risk score had been categorized in Boey, PULP, ASA, MPI scoring system as per standard definitions. Standard postoperative care given along with H. pylori eradication with a 2-weeks triple-drug therapy followed by 6 weeks PPI. Patients were followed-up for 30 days after surgery for any complications. Any significant perioperative event was noted and managed as per institutional practice. Specific complications like mortality or other events in form of organ failure required ICU care and organ support. Similarly, other complications like development of intrabdominal collection required image guided drainage or occasionally re-exploration. Besides these, minor events like surgical site infections, fever, UTI, pneumonia etc. were managed. The data were analyzed using SPSS version 23 . A 95\% confidence interval was taken, and $p$ value less than 0.05 was termed as statistically significant. Chi-square test was used for testing significance of scoring systems. Unpaired $t$ test was used to test the significance of the distribution of scores among different groups (mortality group vs survivor over 30 days and morbidity over 30 -days vs no morbidity). Receiver-operating characteristic (ROC) curve analysis was used to estimate the predictive ability of the scoring system in assessing the postoperative morbidity and mortality.

\section{Results}

A total of 50 operated patients for PPU were included in the study details of which are shown in Table 1 . Various scores had been categorized in groups as per their original description in researched article. The distribution of patients in this study appeared almost normal.

The higher clinical scores (mean \pm S.D) was observed for patients with positive outcomes (mortality or morbidity) compared to patients without. The difference in scores was found statistically significant. Clinical significance of morbidity has been shown in Table 2 .

In the following graphs (Figures 1 and 2), predictability of outcomes by different scoring systems have been illustrated.

\section{Discussion}

Early and accurate identification of patients with increased risk of adverse outcome is needed to plan and target the level of perioperative monitoring and treatment. Thus, a clinical scoring system able to predict the adverse outcome with a high degree of precision is of paramount importance in a resource limited setting like ours. Ideally, score should be easy to calculate, preferably bedside and preoperatively.

Overall 30-day mortality in this study is $18 \%$ which is comparable to $17 \%$ mortality in Buck DL et al. [14], $16 \%$ in Thorsen $\mathrm{K}$ et al. [15] and $14 \%$ in Makela JT et al. [8], Arici C et al. [5] each. A study by Moller $\mathrm{MH}$ et al. [9] involving 2668 patients over a 6-year period had mortality over 30 days of $27 \%$. Regarding the causes of mortality, ARDS was the leading cause in this study. More specifically mortality rate in our study is $5.3 \%, 6.7 \%, 36.4 \%$ and $60 \%$ with Boey score of patients $0,1,2$ and 3 ( $p$-value $=0.08)$. First, being the tertiary referral center, we receive high volume of cases from all over Nepal, most of them often presenting late to us with delayed diagnosis and severe complications. Second, poor resuscitative efforts at previous hospitals and during patient transport may be responsible for increased mortality. Third, limited ICU facilities,

Table 1. Patients characteristics, intraoperative details, postoperative outcomes

\begin{tabular}{|c|c|}
\hline Baseline Characteristics & \\
\hline Age (mean \pm SD) & $45.16 \pm 16.65$ years \\
\hline Sex & Male $92 \%$ \\
\hline Risk Factors & Alcohol - $68 \%$, Smoker - $64 \%$, Previous H/O of PUD - $60 \%$, No Risk - $6 \%$ \\
\hline Comorbidities & 13 patients (DM followed by cardiac diseases and others), 37 - No \\
\hline Duration of perforation (median) & 30 hours (range, $7-360$ hours) \\
\hline Shock at admission & $>24$ hours -29 patients; $>48$ hours -10 patients $22 \%$ \\
\hline \multicolumn{2}{|l|}{ Intraoperative Details } \\
\hline Site of Perforation & $1^{\text {st }}$ part of duodenum (ant) - 41, Stomach (antrum/body) - 5, Juxta-pyloric - 4 \\
\hline Size of perforation & Median $-6.5 \mathrm{~mm}$ (range, $3-25 \mathrm{~mm}$ ); 3 patients $>2 \mathrm{~cm}$ \\
\hline Peritoneal Exudate & Clear - 21, Cloudy purulent - 29, Fecal - none \\
\hline Operative time (mean \pm S.D) & $69.92 \pm 27.34 \mathrm{~min}$ \\
\hline Operative procedure & $\begin{array}{l}\text { Classical Grahams' patch omentopexy }-43 \text {, Modified Grahams' patch omentopexy }-2 \text {, Omentopexy with Gastrojejunostomy }-2 \text {, Peritoneal } \\
\text { Lavage }-1 \text {, Subtotal gastrectomy \& GJ }-1 \text {, Primary repair \& Feeding Jejunostomy }-1\end{array}$ \\
\hline \multicolumn{2}{|l|}{ Score Categorization } \\
\hline Boey $($ Mean \pm S.D) & $1.04 \pm 1.01 ;$ Two or more $-32 \%$; Zero or one $-64 \%$ \\
\hline PULP (Mean \pm S.D) & $3.88 \pm 3.37$ (range, $0-12) ; \leq 6-76 \%, \geq 7-24 \%$ \\
\hline ASA (Mean \pm S.D) & $2.24 \pm 1.29 ; \leq \mathrm{II}-64 \% ; \geq \mathrm{III}-36 \%$ \\
\hline MPI (Mean \pm S.D) & $16.26 \pm 8.19($ range, $4-33) ;<21-62 \%, 21-29-34 \%,>29-4 \%$ \\
\hline \multicolumn{2}{|l|}{ Postop Outcomes } \\
\hline Mortality & 9 cases (ARDS -5 , Refractory Septic Shock -1 , Cardiac Failure -1 , Renal Failure -1 , Others -1 \\
\hline Morbidity & $\begin{array}{l}32 \text { cases (wound infection/ dehiscence }(26 \%) \text {, respiratory failure/ pneumonia }(22 \%) \text {, Fever }(22 \%) \text {, intractable vomiting }(14 \%) \text {, intraabdominal } \\
\text { collection }(12 \%) \text {, paralytic ileus }(12 \%) \text {, acute renal failure, UTI, DVT, anastomotic leak, re-laparotomy, cardiac failure and others. }\end{array}$ \\
\hline & $36 \%$ - No complications \\
\hline Hospital Stay (median) & 8 days (IQR, $6-11$ days) \\
\hline
\end{tabular}


Table 2. Comparison of clinical scores between patients with postoperative complication within 30 days after operation and those without complication (mean \pm SD)

\begin{tabular}{|c|c|c|c|}
\hline Risk Score & Patients with Complication $(\mathbf{n}=\mathbf{3 2})$ & Patients without complication $(\mathbf{n}=\mathbf{1 8})$ & $\boldsymbol{p}$ value \\
\hline Boey & $1.41 \pm 1.04$ & $0.39 \pm 0.50$ \\
\hline PULP & $5.25 \pm 3.33$ & $1.44 \pm 1.65$ \\
\hline ASA & $2.78 \pm 1.21$ & $1.28 \pm 0.75$ & $<0.001$ \\
\hline MPI & $18.78 \pm 7.55$ & $11.78 \pm 7.50$ \\
\hline
\end{tabular}

Table 3. Mortality prediction comparison - ROC curve analysis

\begin{tabular}{|c|c|c|c|c|}
\hline Study $\backslash A U C(95 \%$ CI) & Boey Score & ASA Score & MPI Score & PULP Score \\
\hline $\begin{array}{l}\text { Current Study } \\
\qquad p \text { value }\end{array}$ & $\begin{array}{c}0.802 \\
(0.631-0.973) \\
0.005\end{array}$ & $\begin{array}{c}0.772 \\
(0.639-0.906) \\
0.011\end{array}$ & $\begin{array}{c}0.801 \\
(0.652-0.949) \\
0.005\end{array}$ & $\begin{array}{c}0.810 \\
(0.656-0.965) \\
0.004\end{array}$ \\
\hline Lohsiriwat et al. [16] & 0.86 & 0.91 & 0.84 & - \\
\hline Buck DL et al. [14] & 0.76 & 0.73 & - & - \\
\hline Mishra et al. [17] & 0.85 & - & - & - \\
\hline Moller et al. [9] & 0.70 & 0.78 & - & 0.83 \\
\hline Anbalakan K et al. [18] & 0.72 & 0.75 & 0.77 & 0.75 \\
\hline
\end{tabular}

lack of trained critical care team and perioperative standard technology may have compounded further problems. Also, sub-average nutritional status imposes delayed recovery and subsequent morbidity. Lastly many preexisting comorbid conditions undiagnosed previously may be responsible for underestimation of our risk scoring and lead to overall increased morbidity and mortality.

In the present study, the morbidity rate of PPU patients was $64 \%$ in which wound infections/ dehiscence and pneumonia/ARDS were the leading postoperative complications. Similarly grading complications as Clavien-Dindo classification $32 \%$ had major complications of grade III and above. These findings could be explained by the fact that surgery for PPU is regarded as a contaminated or dirty. Also, chances of nosocomial infections are expected in our hospital setting as compared to different other studies conducted in western and advanced hospital set up. Overall, the postoperative complication rate in the literature ranges from 17-63\% [4]. More specifically, risk of morbidity in our study was found to be $42 \%, 53 \%, 100 \%$ and $100 \%$ with Boey score of $0,1,2$ and 3 respectively ( $p$-value 0.03 )

Mortality prediction by the scoring system was comparable with other similar studies shown in Table 3. Similarly, morbidity prediction by each scoring system found to be statistically significant and was comparable with study by Lohsiriwat et al. [16].

The present study revealed that Boey score, ASA, MPI, and PULP scoring all were capable of predicting poor surgical outcomes, especially Boey score, MPI scoring and PULP score was better than ASA in predicting postoperative mortality. Boey score with scores $\geq$ 2 had sensitivity of $78 \%$ and specificity of $78 \%$ while PULP score of $\geq 7$ had sensitivity of $82 \%$ and specificity of $86 \%$. Though MPI is not specifically designed for evaluating PPU cases, it predicts both mortality and morbidity nearly as accurate as Boey and PULP score. However major drawback of MPI is that it requires intraoperative information; therefore, MPI may not be an ideal preoperative scoring system to identify high-risk patients who might need intensive care prior to the operation. Interestingly, ASA score had best morbidity predictor out of all scoring system in this present study. PULP scoring requires use of laboratory investigations.

With applying the scoring system, high risk patient can be optimized and resuscitation in intensive care unit before planning surgery. Alternatively, high risk patients could be benefited from imaging guided drainage along with ongoing resuscitation and control of sepsis. Also, these scoring systems help to adopt perioperative strategies tailored to individual patient. Similarly, this type study will

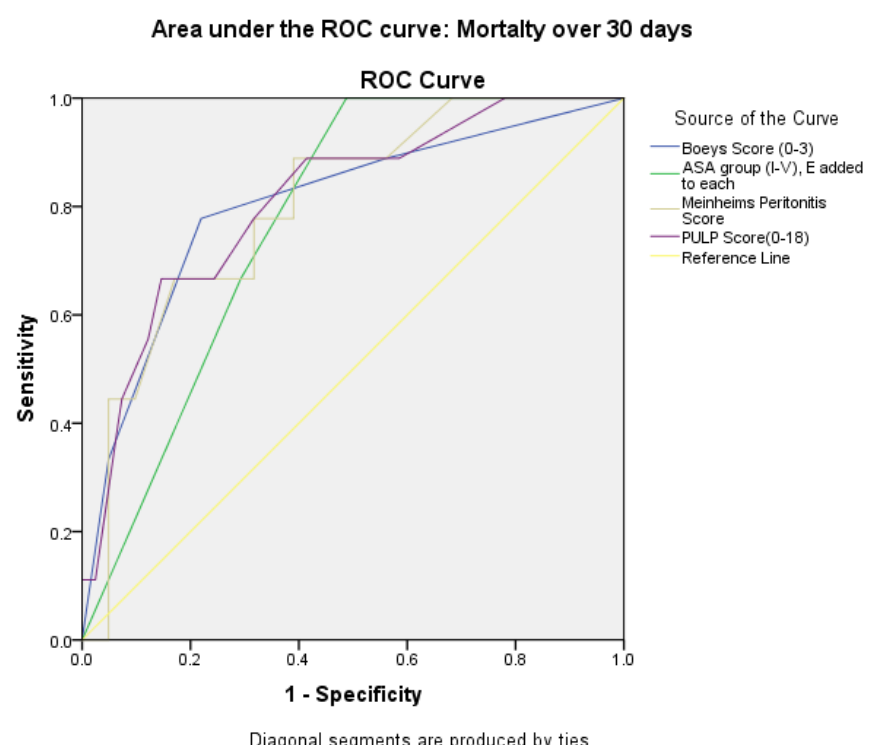

Figure 1. ROC curve analysis of mortality over 30 days

Area under the ROC curve : Morbidity over 30 days

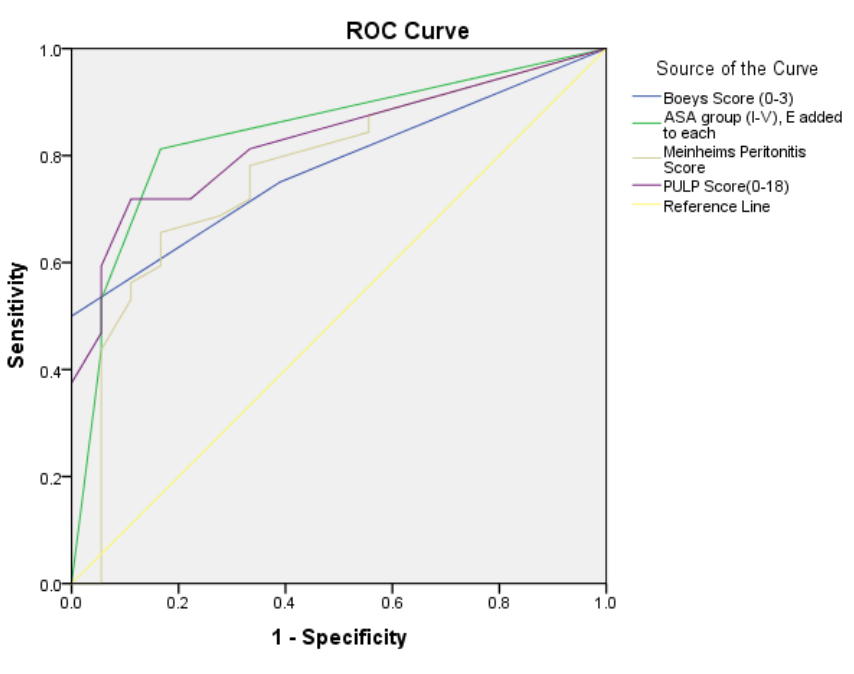

Diagonal segments are produced by ties.

Figure 2. ROC curve analysis of morbidity over 30 days 
help surgeons in periphery set up for early referral to tertiary centers so that perioperative morbidity and mortality could be reduced.

\section{Limitations}

The major limitation of this study is small sample size of just 50 patients due to time constraints and difficulties in patients' follow up. Also, patient nutritional status and BMI are not taken into account which might influence postoperative complications. Laparoscopic surgeries though popular worldwide for PPU, they are not being done in our set up till now. All surgical procedures were performed by open laparotomy by surgical residents/ registrars under guidance of experienced surgeon. Also, being non-interventional study and followup biases are other limitations.

\section{Conclusion}

Increased risk scores increase the risk of morbidity and mortality in patients with perforated peptic ulcer. Boey \& PULP score can be utilized as simple and precise predictor of postoperative mortality and morbidity in PPU patients. Boey scoring system is simple \& can be calculated at bedside preoperatively and can assist in risk stratification. PULP scoring requires use of laboratory investigations. MPI requires intraoperative information. ASA score had best morbidity predictor. In limited resource setting like ours, this can have various implications: it can help us identify high-risk patients preoperatively and help in better use of limited facilities; risk of adverse outcomes can be explained as part of patient counseling, help preoperative optimization in ICU and extensive perioperative care for overall better outcomes.

\section{References}

1. Bertleff MJ, Lange JF (2010) Perforated peptic ulcer disease: a review of history and treatment. Dig Surg 27: 161-169. [Crossref]

2. Møller MH, Adamsen S, Wøjdemann M, Møller AM (2009) Perforated peptic ulcer: how to improve outcome? Scand J Gastroenterol 44: 15-22. [Crossref]

3. Moller MH, Shah K, Bendix J, Jensen AG, Zimmermann-Nielsen E, et al. (2009) Risk factors in patients surgically treated for peptic ulcer perforation. Scand J Gastroenterol 44: 145-152. [Crossref]

4. Di Saverio S, Bassi M, Smerieri N, Masetti M, Ferrara F, et al. (2014) Diagnosis and treatment of perforated or bleeding peptic ulcers: 2013 WSES position paper. World $J$ Emerg Surg 9: 45. [Crossref]
5. Arici C, Mesci A, Dincer D, Dinckan A, Colak T (2007) Analysis of risk factors predicting (affecting) mortality and morbidity of peptic ulcer perforations. Int Surg 92: 147-154. [Crossref]

6. Boey J, Choi SK, Poon A, Alagaratnam TT (1987) Risk stratification in perforated duodenal ulcers. A prospective validation of predictive factors. Ann Surg 205: 22-26. [Crossref]

7. Lee FY, Leung KL, Lai BS, Ng SS, Dexter S, et al. (2001) Predicting mortality and morbidity of patients operated on for perforated peptic ulcers. Arch Surg 136: 90-94. [Crossref]

8. Mäkelä JT, Kiviniemi H, Ohtonen P, Laitinen SO (2002) Factors that predict morbidity and mortality in patients with perforated peptic ulcers. Eur J Surg 168: 446-451. [Crossref]

9. Moller MH, Engebjerg MC, Adamsen S, Bendix J, Thomsen RW (2012) The Peptic Ulcer Perforation (PULP) score: a predictor of mortality following peptic ulcer perforation. A cohort study. Acta Anaesthesiol Scand 56: 655-662. [Crossref]

10. Daabiss M (2011) American Society of Anaesthesiologists physical status classification. Indian J Anaesth 55:111-115. [Crossref]

11. Fitz-Henry J (2011) The ASA classification and peri-operative risk. Ann R Coll Surg Engl 93: 185-187. [Crossref]

12. Billing A, Fröhlich D, Schildberg FW (1994) Prediction of outcome using the Mannheim peritonitis index in 2003 patients. Peritonitis Study Group. Br J Surg 81: 209-213. [Crossref]

13. Linder MM, Wacha H, Feldmann U, Wesch G, Streifensand RA, et al. (1987) [The Mannheim peritonitis index. An instrument for the intraoperative prognosis of peritonitis]. Chirurg 58: 84-92. [Crossref]

14. Buck DL, Vester-Andersen M, Moller MH (2012) Accuracy of clinical prediction rules in peptic ulcer perforation: an observational study. Scand J Gastroenterol 47: 28-35. [Crossref]

15. Thorsen K, Soreide JA, Kvaloy JT, Glomsaker T, Soreide K (2013) Epidemiology of perforated peptic ulcer: age- and gender-adjusted analysis of incidence and mortality. World J Gastroenterol 19: 347-354. [Crossref]

16. Lohsiriwat V, Prapasrivorakul S, Lohsiriwat D (2009) Perforated peptic ulcer: clinical presentation, surgical outcomes, and the accuracy of the Boey scoring system in predicting postoperative morbidity and mortality. World J Surg 33: 80-85. [Crossref]

17. Mishra A, Sharma D, Raina VK (2003) A simplified prognostic scoring system for peptic ulcer perforation in developing countries. Indian J Gastroenterol 22: 49-53. [Crossref]

18. Anbalakan K, Chua D, Pandya GJ, Shelat VG (2015) Five-year experience in management of perforated peptic ulcer and validation of common mortality risk prediction models - are existing models sufficient? A retrospective cohort study. Int J Surg 14: 38-44. [Crossref]

Copyright: (C2018 Sah DN. This is an open-access article distributed under the terms of the Creative Commons Attribution License, which permits unrestricted use, distribution, and reproduction in any medium, provided the original author and source are credited. 